OPEN ACCESS

Edited by:

Daniele Vergara,

University of Salento, Italy

Reviewed by:

Madeleine Duvic,

University of Texas MD Anderson

Cancer Center, United States

Brian Poligone,

Rochester General Hospital Research

Institute (RGHRI), United States

*Correspondence:

Jianfang Sun

fangmin5758@aliyun.com

Hao Chen

CH76CH@163.com

Specialty section:

This article was submitted to

Molecular and Cellular Oncology,

a section of the journal

Frontiers in Cell and Developmental

Biology

Received: 31 July 2021 Accepted: 04 November 2021 Published: 13 December 2021

Citation:

Gan L, Shi H, Zhang Y, Sun J and Chen $H$ (2021) Proteomic Screening and Verification of Biomarkers in Different Stages of Mycosis Fungoides:

A pilot Study.

Front. Cell Dev. Biol. 9:747017. doi: $10.3389 /$ fcell.2021.747017

\section{Proteomic Screening and Verification of Biomarkers in Different Stages of Mycosis Fungoides: A pilot Study}

\author{
Lu Gan, Haoze Shi, Ying Zhang, Jianfang Sun* and Hao Chen* \\ Institute of Dermatology, Chinese Academy of Medical Sciences and Peking Union Medical College, Nanjing, China
}

Mycosis fungoides (MF) is the most common cutaneous T-cell lymphoma; in advanced stages, it can involve multiple organs and has a poor prognosis. Early detection of the disease is still urgent, but there is no optimal therapy for advanced MF. In the present study, quantitative proteomic analyses (label-free quantitation, LFQ) were applied to tissue samples of different stages of MF and tissue samples from controls (eczema patients and healthy donors) to conduct preliminary molecular analysis to clarify the pathogenesis of the disease. Differential protein expression analysis demonstrated that 113 and 305 proteins were associated with the early and advanced stages of MF, respectively. Gene ontology (GO) enrichment analysis was conducted to determine the potential functions of the proteins, which could be classified into three categories: biological process, cellular component, and molecular function. The results revealed that a series of biological processes, including "initiation of DNA replication" and "nucleosome assembly," were involved in the disease. Moreover, cellular components, including the "desmosome" and "integrin complex," may affect the invasion and metastasis of MF via molecular functions, including "integrin binding" and "cadherin binding". Kyoto Encyclopedia of Genes and Genomes (KEGG) pathway enrichment analysis demonstrated that "focal adhesion DNA replication," "Toll-like receptor signalling pathway" and other pathways were also involved. A parallel reaction monitoring (PRM) assay was applied to validate the identified differentially expressed proteins. In conclusion, the above proteomic findings may have great diagnostic and prognostic value in diverse malignancies, especially MF. Nevertheless, further studies are still needed to explore the precise mechanisms of MF.

Keywords: mycosis fungoides, label-free quantitation, parallel reaction monitoring, pathogenesis, treatment

\section{INTRODUCTION}

Mycosis fungoides (MF) is an extranodal, indolent non-Hodgkin lymphoma of $\mathrm{T}$ cell origin and is the most common subtype of cutaneous T- cell lymphoma (CTCL). According to the tumour-nodemetastasis + blood (TNMB) staging system of lymphoma, MF is divided into early stage (stage IAIIA) and advanced stage (stage IIB-IV) subgroups. The increasing prevalence of MF over time has become a new challenge for the global health care system (Ghazawi et al., 2017; Keto et al., 2021). The early stage of MF can simulate a variety of inflammatory diseases, which makes accurate diagnosis relatively difficult (Olsen et al., 2007), while the advanced stage may involve a variety of organs, such as the lymph nodes, peripheral blood or viscera, leading to a poor prognosis (Agar et al., 2010; Trautinger et al., 2017). Moreover, the existing remedies based on multidrug chemotherapy also have 
TABLE 1 | Relevant parameters and instructions for LFQ.

\begin{tabular}{ll}
\hline Item & \\
\hline$>$ Enzyme & - Trypsin \\
$>$ Max missed cleavages & $\bullet 2$ \\
$>$ Main search & $\bullet 4.5 \mathrm{ppm}$ \\
$>$ First search & $\bullet 20 \mathrm{ppm}$ \\
$>$ MS/MS Tolerance & $\bullet 20 \mathrm{ppm}$ \\
$>$ Fixed modifications & $\bullet$ Carbamidomethyl (C) \\
$>$ Variable modifications & $\bullet$ Oxidation (M), Acetyl (Protein N-term) \\
$>$ Database & $\bullet$ Uniprot_HomoSapiens_20,386_20180905 \\
$>$ Database pattern & $\bullet$ Target-Reverse \\
$>$ Include contaminants & $\bullet$ True \\
$>$ Peptide FDR & $\bullet \leq 0.01$ \\
$>$ Protein FDR & $\bullet \leq 0.01$
\end{tabular}

poor long-term effects (Jawed et al., 2014). Hence, reliable biomarkers for early identification and rapid and effective treatments for patients with advanced-stage disease are still urgently needed.

In this study, label-free quantitation (LFQ) analyses were used to investigate the tissue proteomes of patients in different stages to find new biomarkers for early diagnosis and key molecules involved in the pathogenesis and progression of the disease. After preliminarily screening the differentially expressed proteins, parallel reaction monitoring (PRM) was applied to confirm the results.

\section{MATERIALS AND METHODS}

\section{Tissue Collection}

Tissue specimens were collected from patients with MF or eczema and from healthy donors from August 2017 to January 2019 at the Institute of Dermatology, Chinese Academy of Medical Sciences and Peking Union Medical College (Nanjing, China). In this study, to investigate the key pathogenic factors of MF occurrence and progression from the early to advanced stage, we selected 3 healthy donors (group A) and 3 eczema patients (group B) as the control group and 3 patients with early-stage MF (group C) and 3 patients with advanced-stage MF (group D) as the main research objects. Clinical characteristics such as age, sex, clinical stage at the time of diagnosis, disease progression, and treatment were registered for each patient (Supplementary Table S1). The study was approved by the Ethics Committee of the Institute of Dermatology, Chinese Academy of Medical Sciences and Peking Union Medical College (approval no. 2013-LC/KY033). All participating patients gave informed consent.

\section{Sample Preparation}

The samples ( 6 from torso and 6 from limbs, each approximately $0.5 \mathrm{~cm}$ in diameter) were frozen in liquid nitrogen and ground with a mortar and pestle. Five volumes of TCA/acetone (1:9) were added to the powder and mixed by vortexing. The mixture was placed at $-20^{\circ} \mathrm{C}$ for $4 \mathrm{~h}$ and centrifuged at $6,000 \mathrm{~g}$ for $40 \mathrm{~min}$ at $4^{\circ} \mathrm{C}$. The supernatant was discarded. Precooled acetone was added and washed three times. The precipitation was air dried. Thirty volumes of SDT buffer were added to $20-30 \mathrm{mg}$
TABLE 2 | Quantitative protein results by LFQ analysis.

\begin{tabular}{lccc}
\hline Comparisons & Up- & Down- & All- \\
\hline B/A & 93 & 69 & 162 \\
C/A & 130 & 53 & 183 \\
D/A & 281 & 88 & 369 \\
C/B & 80 & 33 & 113 \\
D/B & 281 & 133 & 414 \\
D/C & 196 & 109 & 305
\end{tabular}

Note: Comparison: groups compared; up: upregulated proteins; down: downregulated proteins; all: all differentially expressed proteins.

powder, mixed and boiled for $5 \mathrm{~min}$. The lysate was sonicated and then boiled for $15 \mathrm{~min}$. After centrifugation at $14,000 \mathrm{~g}$ for $40 \mathrm{~min}$, the supernatant was filtered with $0.22 \mu \mathrm{m}$ filters. The filtrate was quantified with the BCA Protein Assay Kit (P0012, Beyotime). The sample was stored at $-20^{\circ} \mathrm{C}$.

\section{SDS-PAGE Separation}

$20 \mathrm{mg}$ of protein from each sample was mixed with $6 \times$ loading buffer and boiled for $5 \mathrm{~min}$. The proteins were separated on a $12.5 \%$ SDS-PAGE gel. The protein bands were visualized by Coomassie Blue R-250 staining.

\section{Filter-Aided Sample Preparation}

Two hundred micrograms of protein for each sample was reduced with $50 \mathrm{mM}$ DTT for $30 \mathrm{~min}$ at $56^{\circ} \mathrm{C}$. The detergent, DTT and other low-molecular-weight components were removed using UA buffer ( $8 \mathrm{M}$ urea, $150 \mathrm{mM}$ Tris- $\mathrm{HCl} \mathrm{pH} \mathrm{8.5)} \mathrm{by} \mathrm{repeated}$ ultrafiltration (Sartorius, $30 \mathrm{kD}$ ). Then, $100 \mu \mathrm{L}$ iodoacetamide (100 mM IAA in UA buffer) was added to block reduced cysteine residues, and the samples were incubated for $30 \mathrm{~min}$ in darkness. The filters were washed with $100 \mu \mathrm{L}$ UA buffer three times and then $100 \mu \mathrm{L} 25 \mathrm{mM}$ NH4HCO3 buffer twice. Finally, the protein suspensions were digested with $4 \mu \mathrm{g}$ trypsin (Promega) in $40 \mu \mathrm{L} 25 \mathrm{mM} \mathrm{NH} 4 \mathrm{HCO} 3$ buffer overnight at $37^{\circ} \mathrm{C}$, and the resulting peptides were collected as the filtrate.

\section{Mass Spectrometry Analysis}

The peptides of each sample were desalted on C18 cartridges, concentrated by vacuum centrifugation and reconstituted in $40 \mu \mathrm{L}$ of $0.1 \%(\mathrm{v} / \mathrm{v})$ formic acid. The peptide content was estimated according to the UV light spectral density at $280 \mathrm{~nm}$ using an extinction coefficient of 1.1 of $0.1 \%(\mathrm{~g} / \mathrm{L})$ solution that was calculated on the basis of the frequency of tryptophan and tyrosine in vertebrate proteins. LC-MS/MS analysis was performed on a Q Exactive Plus mass spectrometer (Thermo Fisher Scientific) that was coupled to Easy nLC (Thermo Fisher Scientific). Two micrograms of peptide was loaded onto a C18 reversed-phase analytical column (Thermo Fisher Scientific, Acclaim PepMap RSLC $50 \mu \mathrm{m} \times 15 \mathrm{~cm}$, nanoViper, $\mathrm{P} / \mathrm{N} 164943)$ in buffer A (0.1\% formic acid) and separated with a linear gradient of buffer $\mathrm{B}$ ( $80 \%$ acetonitrile and $0.1 \%$ formic acid) at a flow rate of $300 \mathrm{~nL} / \mathrm{min}$. The linear gradient was as follows: $5 \%$ buffer B for 5 min, 5-28\% buffer B for 90 min, 28-38\% buffer B for $15 \mathrm{~min}, 38-100 \%$ buffer B for $5 \mathrm{~min}$, and holding in $100 \%$ buffer B for $5 \mathrm{~min}$. MS data were acquired using a data-dependent 

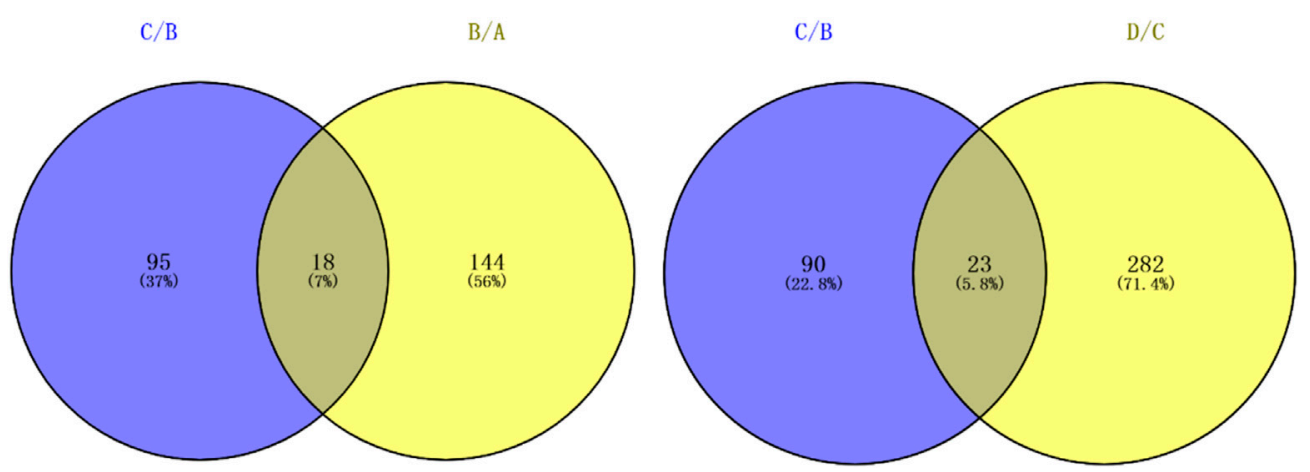

FIGURE 1 | Venn diagrams show the related pathogenic proteins overlapping among groups.

TABLE 3 | Twenty-three significantly overlapping proteins were identified between the $\mathrm{C} / \mathrm{B}$ and $\mathrm{D} / \mathrm{C}$ groups by LFQ analysis.

\begin{tabular}{llllll} 
Main protein ID & Gene name & Fc (C/B) & $\begin{array}{l}\boldsymbol{p} \text { value } \\
\text { (C/B) }\end{array}$ & Fc (D/C) & $\begin{array}{l}\boldsymbol{p} \text { value } \\
\text { (D/C) }\end{array}$ \\
\hline Q96Q06 & PLIN4 & 9.6259 & 0.01693 & 0.0941 & 0.0155 \\
P30838 & ALDH3A1 & 3.3178 & 0.0383 & 0.0546 & 0.0360 \\
Q9BXN1 & ASPN & 2.5884 & 0.0396 & 0.3299 & 0.0032 \\
P07305 & H1F0 & 2.5297 & 0.0053 & 0.2873 & 0.0048 \\
O15533 & TAPBP & 2.5275 & 0.0129 & 1.6607 & 0.0437 \\
P43121 & MCAM & 2.0192 & 0.0135 & 0.4952 & 0.0135 \\
Q9UIJ7 & AK3 & 1.9716 & 0.0423 & 0.5223 & 0.0228 \\
Q96AC1 & FERMT2 & 1.8746 & 0.0106 & 0.4781 & 0.0131 \\
P55268 & LAMB2 & 1.8675 & 0.0390 & 0.3909 & 0.0278 \\
Q13642 & FHL1 & 1.7952 & 0.0065 & 0.2600 & 0.0038 \\
Q9HBL0 & TNS1 & 1.7611 & 0.0271 & 0.2845 & 0.0039 \\
Q9NYU2 & UGGT1 & 1.7197 & 0.0280 & 1.4311 & 0.0314 \\
P62993 & GRB2 & 1.5361 & 0.0076 & 3.5980 & 0.0191 \\
Q12874 & SF3A3 & 1.5010 & 0.0081 & 2.7120 & 0.0377 \\
Q07666 & KHDRBS1 & 1.4771 & 0.0351 & 1.5029 & 0.0204 \\
P05455 & SSB & 1.4291 & 0.0456 & 1.5436 & 0.0020 \\
O00159 & MYO1C & 0.0033 & 0.0155 & 0.5050 & 0.0033 \\
Q08945 & SSRP1 & 1.3621 & 0.0028 & 3.1920 & 0.0346 \\
P61978 & HNRNPK & 1.3050 & 0.0455 & 1.3363 & 0.0429 \\
O75369 & FLNB & 0.7404 & 0.0336 & 0.5533 & 0.0158 \\
P41250 & GARS & 0.6821 & 0.0359 & 1.6045 & 0.0094 \\
Q13835 & PKP1 & 0.6248 & 0.6248 & 0.6248 & 0.0009 \\
Q9Y6G9 & DYNC1LI1 & 0.5905 & 0.0051 & 1.4122 & 0.0283
\end{tabular}

Note: The table shows the main protein IDs, gene names; LFQ, intensities, fold changes, and $\mathrm{p}$ values.

top 10 method, which dynamically selects the most abundant precursor ions from the survey scan $(350-1800 \mathrm{~m} / \mathrm{z}$ ) for higher energy collisional dissociation (HCD) fragmentation. MS1 scans were acquired at a resolution of 70,000 at $\mathrm{m} / \mathrm{z} 200$ with an AGC target of $3 \mathrm{e} 6$ and a max IT of $50 \mathrm{~ms}$. MS2 scans were acquired at a resolution of 17,500 at $\mathrm{m} / \mathrm{z} 200$ with an AGC target of $2 \mathrm{e} 5$ and a $\max$ IT of $45 \mathrm{~ms}$, and isolation width was $2 \mathrm{~m} / \mathrm{z}$. Only ions with a charge state between 2-6 and a minimum intensity of $2 \mathrm{e} 3$ were selected for fragmentation. Dynamic exclusion for selected ions was $30 \mathrm{~s}$. Normalized collision energy was $27 \mathrm{eV}$.

\section{Data Analysis}

MaxQuant software (version 1.5.5.1) was used for database search, and LFQ (Label-Free Quantitation) algorithms (Cox et al., 2014) were used for quantitative analysis. Relevant parameters and instructions were as follows (Table 1). Proteins with fold change $>1.2$ and $p$ value (Student's $t$ test) < 0.05 were considered to be differentially expressed proteins.

\section{Gene Ontology Annotation}

First, all protein sequences were aligned to the Linux database downloaded from NCBI (ncbi-blast-2.3.0+), and only the sequences in the top 10 with $\mathrm{E}$-value $\leq 1 e-3$ were retained. Second, the GO term (database version: go_201,504. obo) of the sequence with the top bit score by Blast2GO was selected (http://www.geneontology.org). Then, the annotation of GO terms to proteins was completed with Blast2GO Command Line. After preliminary annotation, InterProScan (Quevillon et al., 2005) was used to search the EBI database by motif and then add the functional information of motifs to proteins to improve the annotation process. Then, further improvements regarding annotation and connection between GO terms were made with ANNEX. Fisher's exact test was used to assess enriched GO terms by comparing the number of differentially expressed proteins and total proteins correlated with the GO terms.

\section{Kyoto Encyclopedia of Genes and Genomes Pathway Annotation}

Pathway analysis was performed using the KEGG database and KEGG Orthology And Links Annotation (KOALA) software (Kanehisa et al., 2016). Fisher's exact test was used to identify the significantly enriched pathways by comparing the number of differentially expressed proteins and total proteins correlated with the pathways.

\section{Clustering}

The quantitative information for target protein collection was first normalized. Second, Matplotlib software was used to classify the expression levels of samples and proteins (distance algorithm: Euclidean, linkage method: average linkage) and generate the hierarchical clustering heat map.

\section{Trend Analysis}

Short Time-Series Expression Miner (STEM) (Ernst and BarJoseph 2006) was used to carry out significant analysis on the up- 

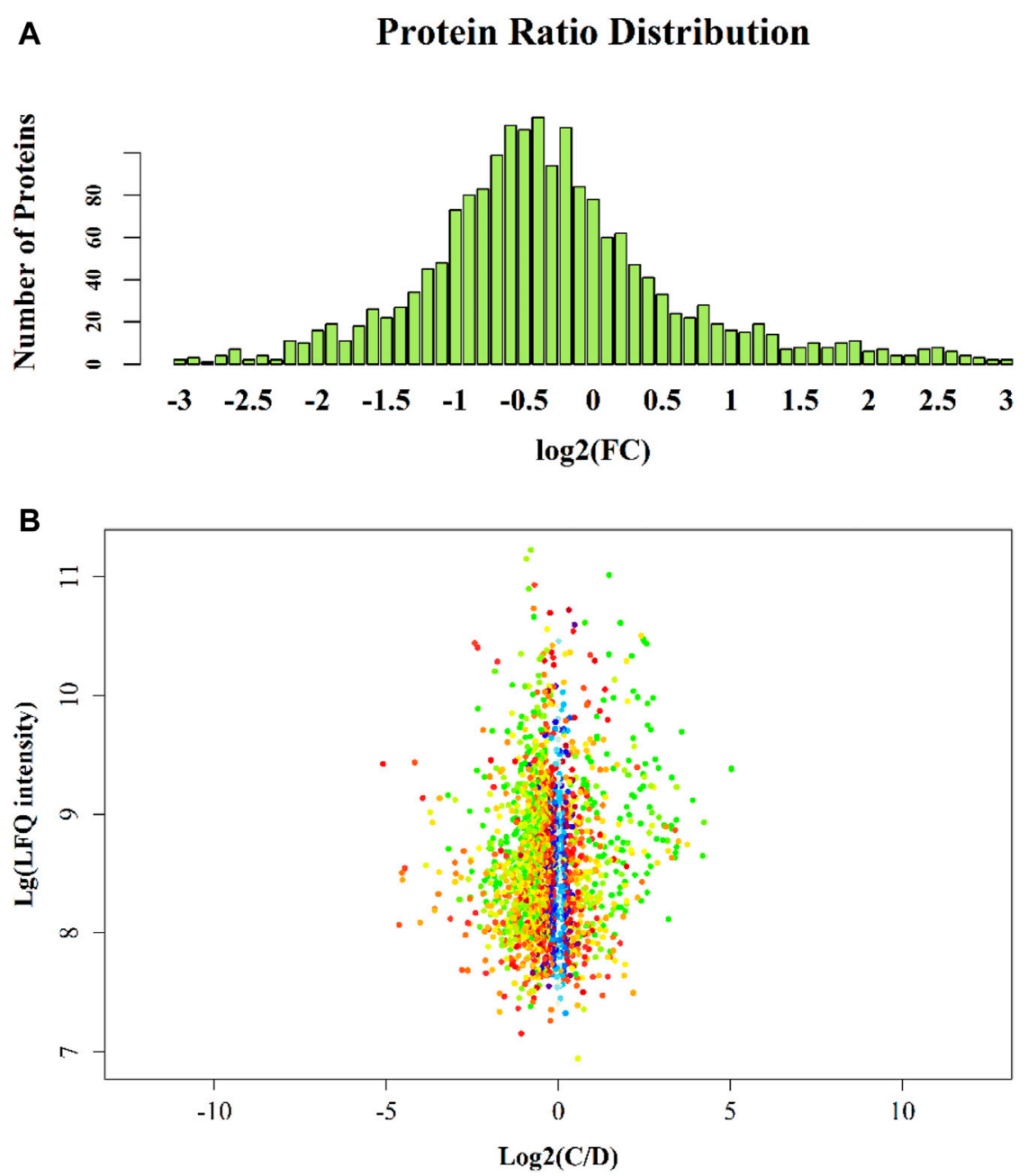

FIGURE 2| Group C vs D protein abundance diagram. Note: The abscissa is the fold change (log base 2-transformed); the ordinate is the number of identified proteins. Figure 2B Group C vs D scatter plot. Note: The variations in the protein expression profiles between group C and D tissue samples were assessed, and scatter plots were constructed to demonstrate the association between the fold changes and LFQ intensities of the differentially expressed proteins. Each data point is marked with a different colour according to the $p$ value obtained by the $t$ test algorithm: blue represents $p$ value $>0.05$; red represents $0.01<p$ value $<0.05$; yellow represents $0.001<p$ value $<0.01$; green represents $p$ value $<0.001$. The abscissa is the fold change (log base 2 -transformed); the ordinate is the sum of LFQ intensity (log base 10 -transformed).

or downregulated proteins to obtain trend models with significant changes.

\section{Parallel Reaction Monitoring}

PRM-MS analysis was conducted following the manufacturer's (Peterson et al., 2012) method, aiming to verify the discovery results. The enzymatic hydrolysate was separated by a nanoUPLC liquid phase system (EASY-nLC1200) and detected using a Q-Exactive Plus mass spectrometer (Thermo Fisher) for MS. Samples were directly loaded onto a $100 \mu \mathrm{m}$ ID $\times 15 \mathrm{~cm}$ reversed-phase chromatographic column (Reprosil-Pur $120 \mathrm{C18}$ ) and separated. Mobile phase $\mathrm{A}$ was a $0.1 \%$ formic acid aqueous solution, and liquid B was a $0.1 \%$ formic acid acetonitrile aqueous solution (acetonitrile was 80\%). The column was balanced with $100 \%$ liquid $\mathrm{A}$. The flow rate was $300 \mathrm{~nL} / \mathrm{min}$, and the gradient time was $120 \mathrm{~min}$. The parameters for mobile phase B were as follows: 6-28\% for $92 \mathrm{~min}, 28-40 \%$ for $20 \mathrm{~min}, 40-100 \%$ for $2 \mathrm{~min}, 100 \%$ for
$2 \mathrm{~min}, 2 \%$ for $2 \mathrm{~min}$. The LC-MS/MS parameters were as follows: analysis time of $120 \mathrm{~min} / \mathrm{sample}$, positive ion detection mode. After nano-UPLC separation, PRM data were collected by MS and imported into Skyline for transition extraction (method match tolerance: $0.055 \mathrm{~m} / \mathrm{z}$ ). The above experiments were performed at Kangcheng Biotech (Shanghai, China). The thresholds for identification of the differentially expressed peptides were set at $p<0.05$ and fold-change $>2$.

\section{RESULTS}

\section{Differentially Expressed Protein Profiles Detected by Label-Free Quantitation Analysis}

There were significantly differentially expressed proteins in the A, B, C, and D groups (Table 2). In total, 113 significantly 


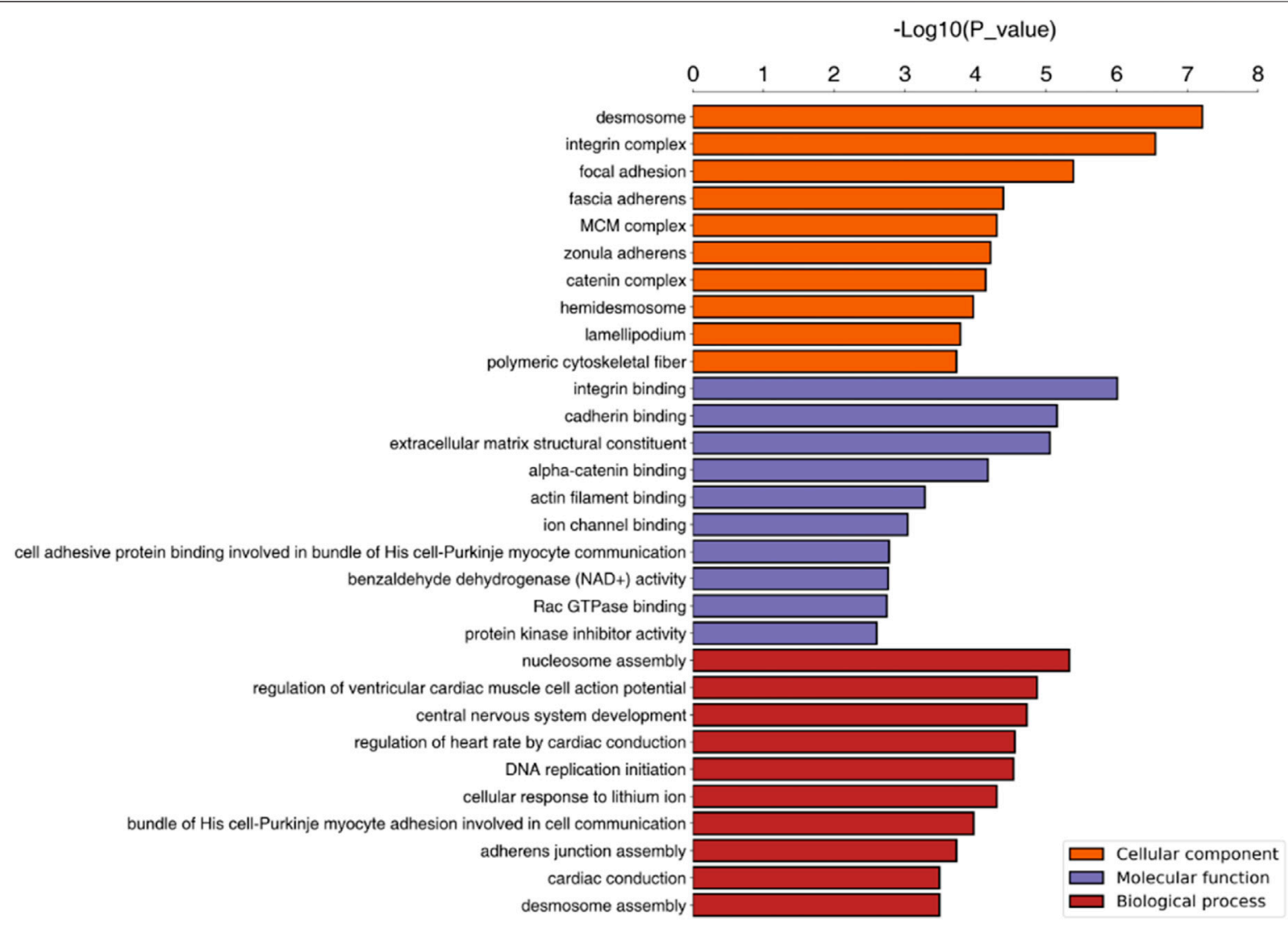

FIGURE 3 | GO enrichment analysis. Note. The top 10 terms associated with differentially expressed proteins are presented. BP, biological process; CC, cellular component; GO, gene ontology.

differentially expressed proteins (80 upregulated and 33 downregulated) were identified from the $\mathrm{C}$ vs $\mathrm{B}$ comparison; 305 significantly differentially expressed proteins (196 upregulated and 109 downregulated) were identified from the $\mathrm{D}$ vs $\mathrm{C}$ comparison. As shown in Figure 1, excluding the overlapping 18 proteins (7\%), 95 differentially expressed proteins (37\%) between groups $\mathrm{C}$ and $\mathrm{B}$, represented the occurrence of the disease. The 23 overlapping proteins $(5.8 \%)$ between groups $\mathrm{C}$ and $\mathrm{B}$ and groups $\mathrm{D}$ and $\mathrm{C}$ groups represented the development of the whole disease process (Table 3). The variations in the protein expression profiles between groups $\mathrm{C}$ and $\mathrm{D}$ were assessed with a protein abundance diagram (Figure 2A), and scatter plots were generated to demonstrate the association between the fold changes and the statistical significance of the differentially expressed proteins (Figure 2B).

\section{Gene Ontology and Kyoto Encyclopedia of Genes and Genomes Pathway Enrichment Analysis}

The cellular component (CC), biological process (BP) and molecular function GO categories were analysed to determine the gene and gene product enrichment. The results of GO enrichment analysis between groups $\mathrm{C}$ and $\mathrm{D}$ are presented in Figure 3; the main enriched BPs were involved in cellular and biological processes, including "DNA replication initiation," "nucleosome assembly" and "cellular response to external stimulus". With regard to CCs, most of these proteins were associated with "desmosomes," the "integrin complex" and "focal adhesion". Terms associated with binding activity, especially "integrin binding," "cadherin binding," "alphacatenin binding" and "extracellular matrix (ECM) structural constituent," were enriched in the molecular function category. The results of KEGG pathway enrichment analysis are presented in Figure $4 \mathrm{~A}$ and indicated the involvement of differentially expressed proteins in "bacterial invasion of epithelial cells," "focal adhesion DNA replication," "Toll-like receptor signalling pathway" and "beta-alanine metabolism." Among them, a number of metabolic pathways were commonly found, and the focal adhesion process was particularly enriched (Figure 4B).

\section{Clustering}

The expression patterns of the differentially expressed proteins were demonstrated in hierarchical clustering (Figure 5).

\section{Trend Analysis}

Different trend models with significant changes in up- or downregulated proteins were carried out as follows (Figure 6, Supplementary Figures S1-2, Supplementary Tables S1A-S2A). 


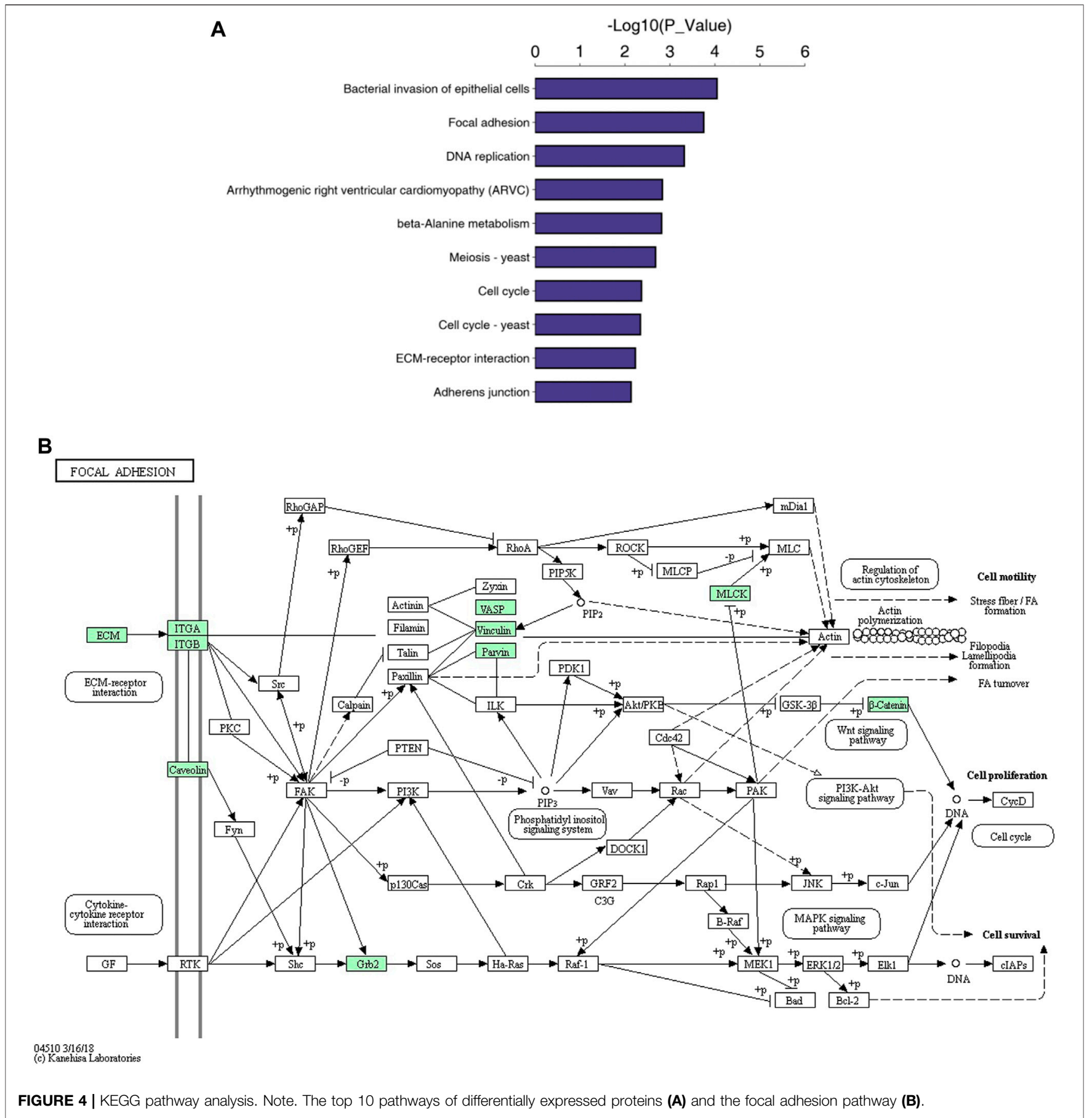

\section{Parallel Reaction Monitoring}

To confirm the previous results and detect the function of proteins expressed in both the early and the advanced stage of MF, 50 selected proteins (Supplementary Table S3) were validated by PRM; these proteins included those with significant changes and those enriched in some specific pathways and components based on the results of bioinformatics analysis. As shown in Table 4 and Figure 7, the concentration of the selected proteins was significantly higher $(p<0.05)$ in group D than in group C, confirming that there was a clear overproduction of related proteins with the progression of the disease. The above findings serve as reliable confirmation of the protein changes determined by LFQ.

\section{DISCUSSION}

MF is a mature $\mathrm{T}$ cell non-Hodgkin lymphoma with presentation in the skin but with potential involvement of the nodes, blood, 


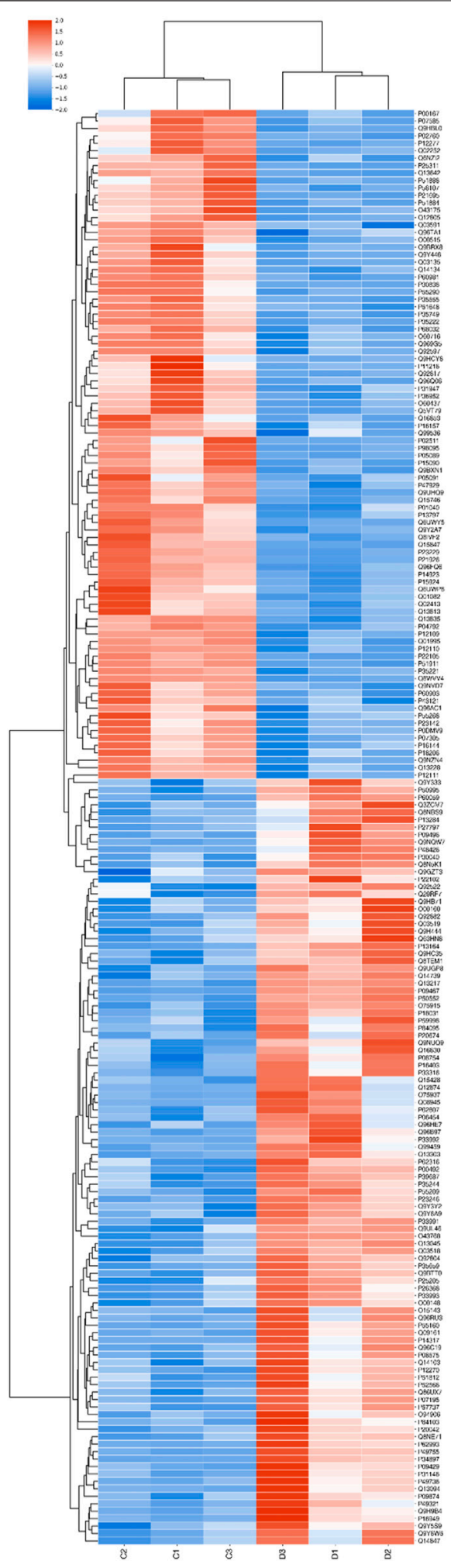

FIGURE 5 | Hierarchical clustering. Note. Proteins differentially expressed in groups $\mathrm{C}$ and $\mathrm{D}$ were subjected to hierarchical clustering. The samples were divided into two groups according to the expression levels of these proteins; red indicates high relative expression, and blue indicates low relative expression. The brightness is positively correlated with the fold change. and viscera in the advanced stage, leading to a poor prognosis. To further explain the mechanism and malignant biological behaviours of MF, quantitative proteomic analyses and confirmatory tests were performed on different stages of MF. Moreover, GO and KEGG pathway enrichment analyses were conducted to highlight the significantly differentially expressed proteins and determine their potential functions.

As mentioned above, differential expression analysis demonstrated that 113 and 305 proteins were associated with early and advanced MF, respectively. In addition, we speculated that the remaining 95 proteins that differed between groups $\mathrm{C}$ and $\mathrm{B}$ may indicate the occurrence of the disease, while the overlapping 23 proteins may help predict the progression and prognosis of MF. GO enrichment analysis was used to identify the functions of the proteins and their roles in the progression of the disease. Relevant proteins that were up- or downregulated and their functions in multiple malignancies are summarized below (Table 5).

The enriched CC terms were associated with CCs and molecules connected with the extracellular region, especially the "integrin complex," "focal adhesion," and the "MCM complex." As in previous studies, integrins and integrin-linked kinase (ILK) were essential for invasion because they mediated physical interactions with the ECM and regulated oncogenic signalling pathways (Desgrosellier and Cheresh 2010; Choi et al., 2012). Targeting integrin $\beta 4$ (ITGB4) combined with ILK could increase the latent tumorigenic potential and decrease the invasive potential in cancer. In CTCL, activation of T-cell integrins facilitates T-cell adhesion to skin endothelial cells and subsequent binding to ECM proteins, which regulates a diverse array of cellular functions and modulates the tumour microenvironment (Hwang et al., 2008; Ni et al., 2008; Ansell and Lin, 2020). During the process, focal adhesion kinase (FAK), which localizes at contact points of cells with the ECM, also plays a critical role in cell survival, motility and metastasis and is upregulated in numerous types of human tumours (Eke and Cordes, 2015). In addition, the CC terms of the MCM complex were particularly prominent. Normally, the cellular levels of MCM proteins depend on the cell status (their levels are higher in proliferating cells and much lower in quiescent, differentiated or senescent cells). This makes MCM proteins useful markers of cell proliferation, and therefore, evaluation of MCM levels could help detect various precancerous states and preinvasive and invasive neoplasms. Numerous studies have pointed out that MCM is more specific and sensitive than conventional proliferative markers such as Ki-67 and PCNA.

In terms of molecular function, "protein binding" and "enzyme binding" terms including "cadherin binding," "ECM structural constituent," and "integrin binding" were enriched among the differentially expressed proteins. These proteins and their downstream signalling pathways mainly influence the regulation of contact inhibition. Among them, E-cadherin is a key component of adherens junctions, the loss of which results in increased cell motility and cancer progression (Mendonsa et al., 2018). Other significantly differentially expressed proteins included collagen type VI alpha 1 (COL6A1), which is localized in the ECM and involved in cell 

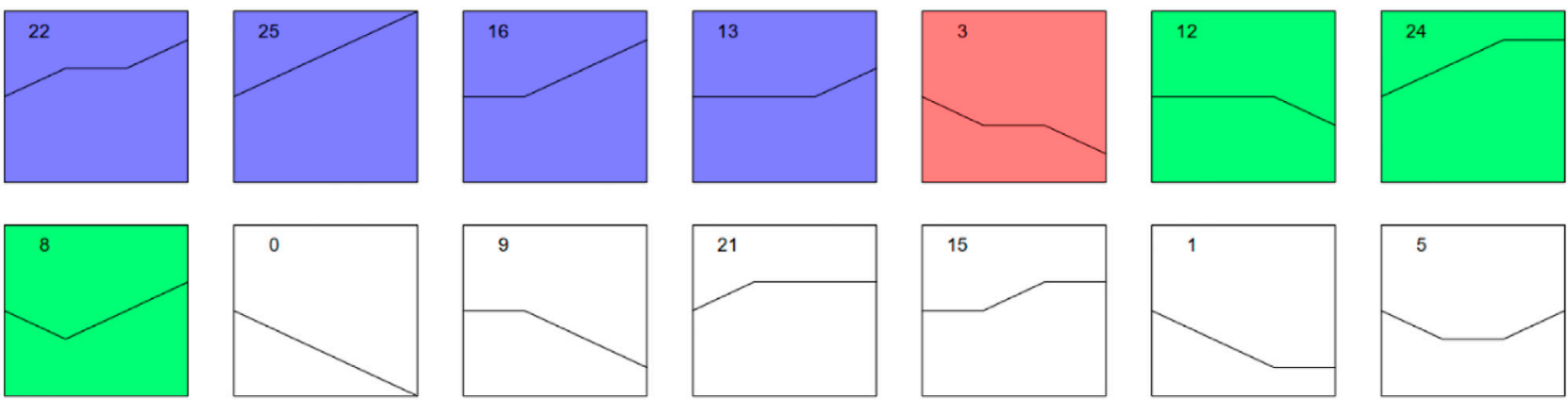

FIGURE 6 | Trend models with significance of protein expressions. Note: Each block diagram in the figure represents a trend profile. The number in the upper left corner is the number of profiles. Different groups were labelled by STEM according to the trend and significance level of each profile. Those with the same colour showed similar significant trends, while those without colour showed nonsignificant trends. STEM, Short Time-Series Expression Miner.

TABLE 4 | Detailed lists of significantly expressed proteins.

\begin{tabular}{lcc} 
Protein Name & Fold change (D/C) & p.value (D/C) \\
\hline SERPINB5 & 2.422824979 & 0.010797906 \\
SSRP1 & 2.267709861 & 0.044248565 \\
ITGB4 & 0.375482894 & 0.031100313 \\
COL6A1 & 0.170598304 & 0.036254626 \\
PLIN4 & 0.170637917 & 0.00050838 \\
MCM3 & 3.345329674 & 0.03005326 \\
TNXB & 0.189852295 & 0.030431991 \\
MCM5 & 6.908794219 & 0.028524297 \\
UGGT1 & 2.645307058 & 0.038085875 \\
KHDRBS1 & 0.351991202 & 0.017846017 \\
MCM2 & 6.195499826 & 0.034073626 \\
STMN1 & 4.636626485 & 0.020608702 \\
H1F0 & 0.417768823 & 0.046817625 \\
ITGA6 & 0.472315349 & 0.024424589 \\
ALDH3A1 & 0.132337909 & 0.00699105 \\
CD44 & 1.85356264 & 0.04913183
\end{tabular}

adhesion and collagen remodelling (Cescon et al., 2015; Lamande and Bateman 2018). COL6A1 may play an important role in the metastatic process and could be considered a predictor of poor outcomes in several cancers (Edoo et al., 2019; Hou et al., 2016). Notably, some studies have revealed that the transcription factor c-Jun-bound p300 increases the enrichment of H3K27ac at the promoter region of COL6A1, thus resulting in the upregulation of COL6A1 in osteosarcoma (OS). Furthermore, COL6A1 promotes OS metastasis by suppressing STAT1 by promoting its ubiquitination proteasome degradation (Zhang et al., 2021). In our study, the trend in STAT1 expression was consistent with the above findings. Therefore, we speculated that COL6A1, as a link between the H3K27 acetylation process and the JAK-STAT pathway, might serve as a new therapeutic target for MF.

We found that most of the BP terms were associated with "DNA replication initiation" and "nucleosome assembly." Among these proteins, MCM family proteins are vital for the process of DNA replication and are often called replicationlicensing proteins. Additionally, the regulation of DNA replication is closely connected with the histone acetylation process. As was found in this study, with the progression of tumours, the difference in HDAC1 gradually became significant. To date, a variety of histone deacetylase inhibitors (HDACis) have been used clinically in the treatment of T-cell lymphoma (Hristov et al., 2019). Therefore, further studies focused on the oncogenic roles of these processes and the potential use of HDACis for the treatment of MF are needed. In addition, the process of "nucleosome assembly," which is affected by multiple proteins-mainly the high mobility group nucleosome-binding (HMGN) proteins, modulates the cellular epigenetic profile, changes gene expression and impacts biological processes such as development and the cellular response to environmental and hormonal signals (Postnikov and Bustin 2010). Thus, the HMGN family and its regulatory pathways may play a positive role in cell proliferation and invasion in lymphoma.

KEGG pathway enrichment analysis revealed that pathways such as 'focal adhesion', "ECM-receptor interaction," "adherens junctions," "DNA replication," the "cell cycle" and the "bacterial invasion of epithelial cells" were closely associated with the differentially expressed proteins. The migration, invasion and metastasis of tumour cells lead to tumorigenesis. Multifunctional focal adhesion complexes facilitating cell-ECM contact and the connection between the ECM and actin cytoskeleton play mechanistically key roles, as they structurally and functionally control cell morphology and cytoplasmic signalling. During this process, focal adhesion kinase plays an important role in Erb-2/ Erb3-induced oncogenic transformation and invasion and can block the p53 transcriptional activity of p21, BAX and Mdm-2 (Benlimame et al., 2005; Golubovskaya and Cance 2010). Moreover, as discussed above, MCM family proteins interact with many molecules involved in DNA replication and cell cycle regulation (Hyrien 2016; Aporowicz et al., 2019). We compared our results with those of previous studies (Andrews et al., 2019), and we found that genes with significant changes were related to the apoptosis, cell cycle, cytokine/chemokine signalling, especially the ECM and cell adhesion/migration pathways, consistent with our results; these genes included MCM2, MCM4, CDK1, CDK6 (cell cycle), CDK1, CDK6, PERP, RRM2, SERPINB5 (p53 signalling pathway), ITGB4, ITGA6, LAMA5 (ECM-receptor interaction), and CFH, CAMP, C1QC (bacterial invasion of epithelial cells). These genes may play a role 

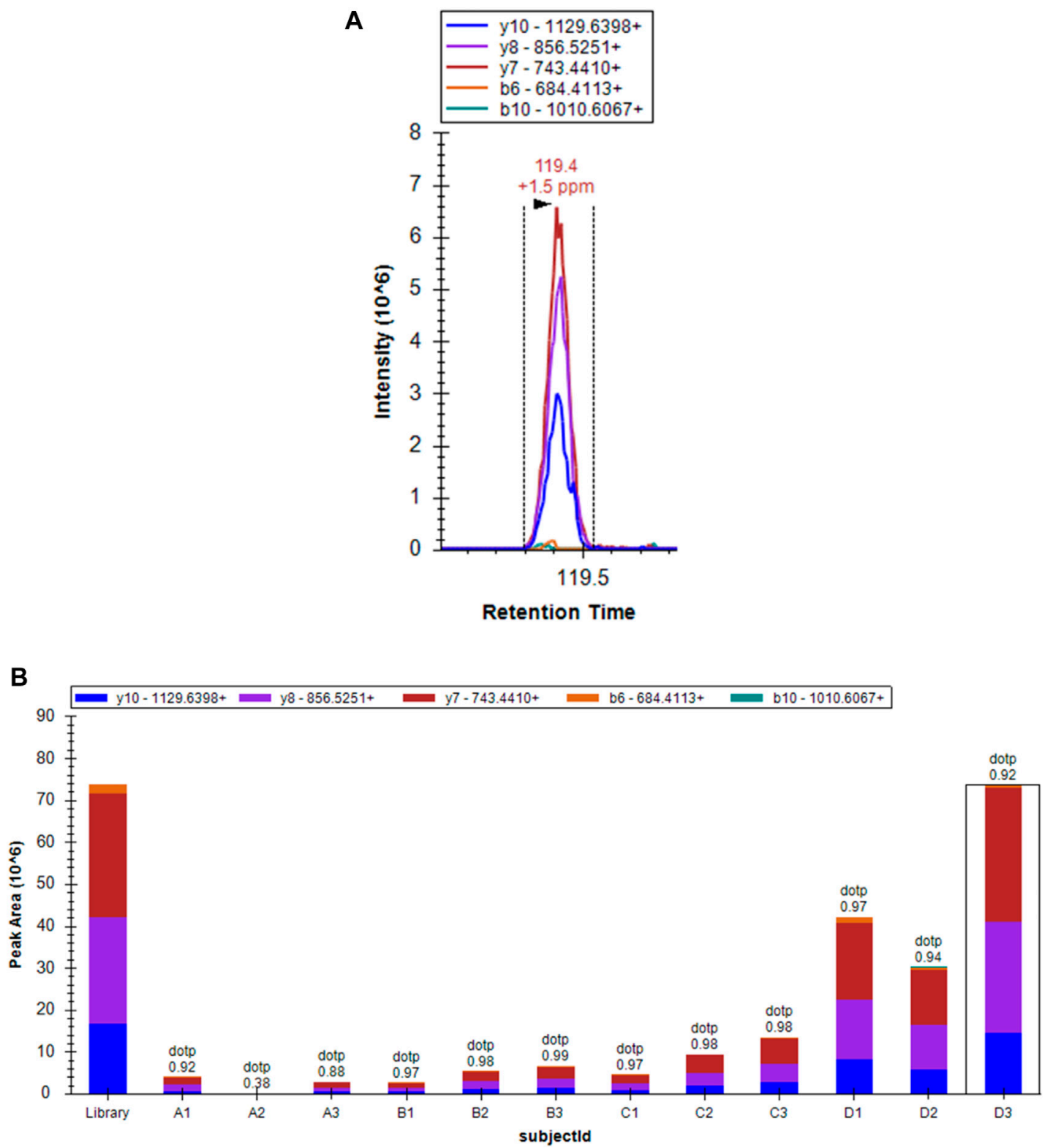

FIGURE 7 | Spectral peak figure shows the expression of MCM3 in the sample D3 Figure 7B Histogram showing the expression of MCM3 in different groups.

in the variable manifestations of MF in the skin, lymph nodes, and peripheral blood.

The results verified by PRM were consistent with those of the quantitative proteomic analysis, which proved the reliability of the above analysis. We also identified a series of meaningful proteins that have been previously found to be associated with MF. Networks including MAPK, PI3K/Akt, JAK/STAT, NF- $\mathrm{B}$, TCR, and TLR downstream signalling were activated in malignant T-cells, facilitating ECM remodelling and tumour progression (Bastidas et al., 2018; Seto et al., 2018; Kamijo et al., 2018; Perez et al., 2020; Rendon-Serna et al., 2021). The screening of ZAP70 also drew our attention, as it was recently found to be a regulatory point of non-Hodgkin lymphoma that acts via the Ras-Raf-dependent pathway and to induce cell apoptosis (Bharti et al., 2016). In particular, although STAT1, STAT2, STAT3, STAT5, and STAT6 were screened in our study and were already reported to be involved in several MF studies, they did not show significant expression trends among the compared groups but increased significantly in group B, reflecting their involvement in inflammatory diseases (Bastidas et al., 2018; Garcia-Colmenero et al., 2020; Gaydosik et al., 2020; Rendon-Serna et al., 2021).

In this study, through intergroup comparison and trend analysis, we also revealed other meaningful results that may explain the mechanism and progression of MF from a new perspective. In some trend models, we found that the 
TABLE 5 | Relevant proteins and their functions in GO enrichment analysis.

\begin{tabular}{|c|c|c|c|c|c|c|}
\hline GO term & Category & $p$ value & Gene names & Mechanisms & Malignancies & References \\
\hline $\begin{array}{l}\text { Integrin } \\
\text { complex }\end{array}$ & $\mathrm{CC}$ & $<0.0001$ & $\begin{array}{l}\text { TNXB, MYH11, } \\
\text { ITGA6, ITGB4, } \\
\text { DSP, etc. }\end{array}$ & $\begin{array}{l}\text { These factors mediate physical } \\
\text { interactions with the ECM and } \\
\text { regulate the proliferation, } \\
\text { migration, and invasion of tumour } \\
\text { cells by inhibiting the } \\
\text { phosphorylation of series of } \\
\text { downstream signalling targets, } \\
\text { increasing the expression of MMP- } \\
2 \text { and MMP- } 9 \text {, and reducing the } \\
\text { expression of caspase- } 3\end{array}$ & $\begin{array}{l}\text { Ovarian cancer, cervical } \\
\text { cancer, breast cancer, } \\
\text { lung cancer }\end{array}$ & $\begin{array}{l}\text { Desgrosellier and Cheresh 2010; } \\
\text { Choi et al., 2012; Yan et al., } 2019\end{array}$ \\
\hline
\end{tabular}

\begin{tabular}{|c|c|c|c|c|c|c|}
\hline Focal adhesion & CC & $<0.0001$ & $\begin{array}{l}\text { EVPL, MYH11, } \\
\text { CRYAB, CNN1, } \\
\text { ANXA8LA, } \\
\text { EPPK1, etc. }\end{array}$ & $\begin{array}{l}\text { These factors increase to the } \\
\text { activity of ERK } 1 / 2 \text {, whose } \\
\text { secretion is promoted by MMP-9, } \\
\text { or upregulate PI3K and Akt and } \\
\text { were positively correlated with cell } \\
\text { invasiveness }\end{array}$ & $\begin{array}{l}\text { Breast cancer, lung } \\
\text { cancer, prostate cancer, } \\
\text { ovarian cancer, etc. }\end{array}$ & $\begin{array}{l}\text { Hwang et al., 2008; Ni et al., 2008, } \\
\text { Ansell and Lin 2020; Eke and Cordes } \\
\text { 2015; Zhang et al. (2019) }\end{array}$ \\
\hline MCM complex & $\mathrm{CC}$ & $<0.0001$ & $\begin{array}{l}\text { MCM2, MCM3, } \\
\text { MCM4, MCM5 }\end{array}$ & $\begin{array}{l}\text { These factors play different roles in } \\
\text { cellular processes such as: } \\
\text { chromatin remodelling, DNA } \\
\text { repair, DNA transcription, RNA } \\
\text { processing, and cell cycle } \\
\text { regulation }\end{array}$ & $\begin{array}{l}\text { Adrenocortical cancer, } \\
\text { CTCL, oral cancer }\end{array}$ & $\begin{array}{l}\text { Aporowicz et al., 2019; Hyrien 2016; } \\
\text { Jankowska-Konsur et al., 2015; } \\
\text { Niranjan et al. (2018) }\end{array}$ \\
\hline Integrin binding & MF & $<0.0001$ & $\begin{array}{l}\text { FBLN1, FBLN2, } \\
\text { FBN1, ITGA6, DSP, } \\
\text { TNXM, etc. }\end{array}$ & $\begin{array}{l}\text { These factors belong to a family of } \\
\text { extracellular glycoproteins that } \\
\text { modulate cell morphology, cellular } \\
\text { interaction with the ECM and cell } \\
\text { migration }\end{array}$ & $\begin{array}{l}\text { Colorectal cancer, } \\
\text { urothelial cancer, lung } \\
\text { cancer, ovarian } \\
\text { cancer, etc. }\end{array}$ & $\begin{array}{l}\text { Desgrosellier and Cheresh 2010, } \\
\text { Choi et al., 2012, Watany et al., } 2018\end{array}$ \\
\hline $\begin{array}{l}\text { Cadherin } \\
\text { binding }\end{array}$ & MF & $<0.0001$ & $\begin{array}{l}\text { JUP, CTNNA1, } \\
\text { CTNNB1, ANK1, } \\
\text { CDH13, NDRG1, etc. }\end{array}$ & $\begin{array}{l}\text { The cytoplasmic tail of E-cadherin } \\
\text { is associated with various catenins } \\
\text { ( } \alpha, \beta \text {, and } \mathrm{p} 120 \text { ) that link to the } \\
\text { cytoskeleton and mediate } \\
\text { downstream signalling including } \\
\text { the Hippo, Wnt, TGF } \beta \text {, NF-kB, and } \\
\text { other growth factor signalling } \\
\text { pathways }\end{array}$ & $\begin{array}{l}\text { Bladder cancer, gastric } \\
\text { cancer, breast cancer }\end{array}$ & $\begin{array}{l}\text { Mendonsa et al., 2018; Chi et al., } \\
\text { 2020; Clark et al., 2020; Mendonsa } \\
\text { et al. (2018) }\end{array}$ \\
\hline $\begin{array}{l}\text { ECM structural } \\
\text { constituent }\end{array}$ & $\mathrm{MF}$ & $<0.0001$ & $\begin{array}{l}\text { FBLN1, FBLN2, } \\
\text { PRELP, COL6A1, } \\
\text { COL6A2, LAMB2, etc. }\end{array}$ & $\begin{array}{l}\text { These factors stimulate cell motility } \\
\text { and support distant colonization by } \\
\text { regulating the expression of } \\
\text { oncogenic transcription factors, } \\
\text { tumour suppressor p53, and } \\
\text { SMAD family member } 4\end{array}$ & $\begin{array}{l}\text { Prostate cancer, renal } \\
\text { cancer, cervical cancer, } \\
\text { osteosarcoma }\end{array}$ & $\begin{array}{l}\text { Edoo et al., 2019; Hou et al., 2016; } \\
\text { Birnbaum et al., } 2011\end{array}$ \\
\hline $\begin{array}{l}\text { Nucleosome } \\
\text { assembly }\end{array}$ & $\mathrm{BP}$ & $<0.0001$ & $\begin{array}{l}\text { H1F0, H1FX, HMGB1, } \\
\text { HIST1H2BC, } \\
\text { H1ST1H1C, } \\
\text { NAP1L1, etc. }\end{array}$ & $\begin{array}{l}\text { These factors enhance proliferation } \\
\text { while inhibiting the apoptosis of } \\
\text { cancer cells through the } \\
\text { upregulation of MMP-9 activity }\end{array}$ & $\begin{array}{l}\text { Gastric cancer, bladder } \\
\text { cancer }\end{array}$ & $\begin{array}{l}\text { Rochman et al., 2010; Liu et al., } \\
\text { 2019; Wahafu et al., } 2011\end{array}$ \\
\hline $\begin{array}{l}\text { DNA replication } \\
\text { initiation }\end{array}$ & $\mathrm{BP}$ & $<0.0001$ & $\begin{array}{l}\text { MCM2, MCM3, } \\
\text { MCM4, MCM5, } \\
\text { MCM7 }\end{array}$ & $\begin{array}{l}\text { MCM-3 is phosphorylated by } \\
\text { cyclin B/CDK1 and plays a } \\
\text { regulatory role in MCM2-7 } \\
\text { complex. MCM- } 5 \text {, in cooperation } \\
\text { with cyclin E, associates with the } \\
\text { centrosome and regulates its } \\
\text { duplication. MCM-7 interacts with } \\
\text { many molecules involved in cell } \\
\text { cycle regulation, including pRb, } \\
\text { Mat-1 and FLH. }\end{array}$ & $\begin{array}{l}\text { Adrenocortical cancer, } \\
\text { CTCL, oral cancer }\end{array}$ & $\begin{array}{l}\text { Lan and Wang 2020; Aporowicz } \\
\text { et al., 2019; Hyrien 2016; Niranjan } \\
\text { et al., 2018; Jankowska-Konsur } \\
\text { et al., } 2015\end{array}$ \\
\hline $\begin{array}{l}\text { Adherens } \\
\text { junction }\end{array}$ & $\mathrm{BP}$ & 0.0002 & JUP, VCL, CTNNB1 & $\begin{array}{l}\text { As cell-cell junction proteins, they } \\
\text { are involved in adhesion junction }\end{array}$ & $\begin{array}{l}\text { Colon cancer, gastric } \\
\text { cancer }\end{array}$ & $\begin{array}{l}\text { Peterson et al., 2012; Lan and Wang } \\
\text { 2020; Hristov et al., } 2019\end{array}$ \\
\hline
\end{tabular}

assembly and desmosome composition, the loss of which results in increased $p$-AKT levels and AKT/GSK3 $\beta /$ $\beta$-catenin signalling activity

$\begin{array}{ll}\begin{array}{l}\text { Colon cancer, gastric } \\ \text { cancer }\end{array} & \text { Peterson et al., 2012; Lan } \\ & \text { 2020; Hristov et al., } 2019\end{array}$ 
expression of several proteins was initially not significantly different according to our thresholds but gradually changed remarkably with the progression of the disease. In profile 22, DDX39A was apparently overexpressed after a plateau. As a new member of the DEAD box RNA helicases, it plays a role in RNA splicing/export and is involved in the pathogenesis of cancers, including bladder cancer (Sugiura et al., 2007; Kato et al., 2012). In addition, it was found to be positively related to a poor prognosis via the regulation of cell proliferation, G2/M cell cycle arrest, caspase-mediated cell apoptosis, and cell invasion and migration in melanoma (Xing et al., 2020). Haematopoietic cell-specific lyn substrate-1 (HCLS1), another protein in profile 22 , is important for the activation of GTPases and integrins and mediates the downstream signalling of many receptors, including BCR, TCR, and CXCR4 (Castro-Ochoa et al., 2019). In profile 25, PARP1, as the main poly (ADP-ribose) polymerase molecule, could influence many processes, including genome maintenance, replication, transcription, and chromatin remodelling, which makes it a central regulatory hub in many cancer-relevant processes (Engbrecht and Mangerich, 2020). Proteomic analyses in aggressive MF demonstrated that PARP-1 was overexpressed in patients with early-stage MF and may serve not only as a biomarker at initial biopsy for a disease that may become aggressive but also as a new therapeutic target for advanced MF(Lemchak et al., 2018). In addition, heat-shock protein family A (Hsp70) member 1 like (HSAP1L), Hsp70 member 1A (HSPA1A), and ATP-dependent RNA helicase (DDX17) had higher expression in aggressive disease versus nonaggressive (Lemchak et al., 2018), similar to what we found in this study.

In conclusion, the present study was conducted to compare protein expression in different stages of MF, and to screen out and verify the differentially expressed proteins. The results revealed that genes and proteins implicated in DNA replication initiation, nucleosome assembly, and cell adhesion activity, together with the CCs and molecules that connect extracellular regions may be involved in the pathogenesis and metastasis of MF via the regulation of apoptosis, the cell cycle, and cell adhesion/ migration pathways. Some special proteins showed obvious differences from early -stage to advanced-stage MF, indicating that they may be the key molecules related to the progression of the disease. Research on the pathogenesis and treatment of MF is still worth furtherstudy. We believe that proteomics is a powerful tool to identify potential biomarkers for diagnosis and that these molecules may be promising therapeutic targets for MF. Further studies are still needed to determine their application value.

\section{Limitations of Our Study}

The present study only involved an LFQ analysis and subsequent GO analysis, KEGG analysis, clustering analysis, trend analysis,

\section{REFERENCES}

Agar, N. S., Wedgeworth, E., Crichton, S., Mitchell, T. J., Cox, M., Ferreira, S., et al. (2010). Survival Outcomes and Prognostic Factors in Mycosis Fungoides/ Sézary Syndrome: Validation of the Revised International Society for and an initial verification by PRM. The sample size was relatively small, and further research on the function of the target proteins could be performed in our future studies to substantiate these findings.

\section{DATA AVAILABILITY STATEMENT}

The original contributions presented in the study are publicly available. This data can be found here: ProteomeXchange dataset PXD027714.

\section{ETHICS STATEMENT}

The studies involving human participants were reviewed and approved by the Ethics Committee of the Institute of Dermatology, Chinese Academy of Medical Sciences and Peking Union Medical College (approval no.2013-LC/KY-033). All participating patients gave informed consent. The patients/ participants provided their written informed consent to participate in this study.

\section{AUTHOR CONTRIBUTIONS}

LG and HC conceived and devised the study. LG, YZ, and HC performed the bioinformatic and statistical analysis. LG, HS, and $\mathrm{HC}$ found related data and analysis tools. LG, JS and HC supervised the research and wrote the manuscript. All authors contributed to the article and approved the submitted version.

\section{FUNDING}

The present study was supported by grants from The Nanjing Incubation Program for National Clinical Research Center (2019060001); The present study was supported by grants from CAMS Innovation Fund for Medical Sciences (CIFMS-2017-I2M-1017); Six Peak talents Project of Jiangsu Province (No.WSN-030); Postgraduate Innovation Fund of Peking Union Medical College (3301030202026).

\section{SUPPLEMENTARY MATERIAL}

The Supplementary Material for this article can be found online at: https://www.frontiersin.org/articles/10.3389/fcell. 2021.747017/full\#supplementary-material

Cutaneous Lymphomas/European Organisation for Research and Treatment of Cancer Staging Proposal. Jco 28, 4730-4739. doi:10.1200/jco.2009.27.7665 Andrews, J. M., Schmidt, J. A., Carson, K. R., Musiek, A. C., Mehta-Shah, N., and Payton, J. E. (2019). Novel Cell Adhesion/migration Pathways Are Predictive Markers of HDAC Inhibitor Resistance in Cutaneous T Cell Lymphoma. EBioMedicine 46, 170-183. doi:10.1016/j.ebiom.2019.07.053 
Ansell, S. M., and Lin, Y. (2020). Immunotherapy of Lymphomas. J. Clin. Invest. 130, 1576-1585. doi:10.1172/jci129206

Aporowicz, M., Czopnik, P., Kubicka, E., Piotrowska, A., Dziegiel, P., Bolanowski, M., et al. (2019). Minichromosome Maintenance Proteins MCM-3, MCM-5, MCM-7, and Ki-67 as Proliferative Markers in Adrenocortical Tumors. Anticancer Res. 39, 1151-1159. doi:10.21873/anticanres.13224

Bastidas Torres, A. N., Najidh, S., Tensen, C. P., and Vermeer, M. H. (2018). Molecular Advances in Cutaneous T-Cell Lymphoma. Sem Cutan. Med. Surg. 37, 81-86. doi:10.12788/j.sder.2018.007

Benlimame, N., He, Q., Jie, S., Xiao, D., Xu, Y. J., Loignon, M., et al.(2005).FAK Signaling Is Critical for ErbB-2/ErbB-3 Receptor Cooperation for Oncogenic Transformation and Invasion. J. Cel Biol, 171, 505-516.

Bharti, B., Shukla, S., Tripathi, R., Mishra, S., Kumar, M., Pandey, M., et al. (2016) Level of PAX5 in Differential Diagnosis of Non-hodgkin's Lymphoma. Indian J. Med. Res., 143, S23-S31.doi:10.4103/0971-5916.191747

Birnbaum, D. J., Adélaïde, J., Mamessier, E., Finetti, P., Lagarde, A., Monges, G., et al. (2011). Genome Profiling of Pancreatic Adenocarcinoma. Genes Chromosom. Cancer 50, 456-465. doi:10.1002/gcc.20870

Castro-Ochoa, K. F., Guerrero-Fonseca, I. M., and Schnoor, M. (2019). Hematopoietic Cell-specific Lyn Substrate (HCLS1 or HS1): A Versatile Actin-Binding Protein in Leukocytes. J. Leukoc. Biol. 105, 881-890. doi:10.1002/JLB.MR0618-212R

Cescon, M., Gattazzo, F., Chen, P., and Bonaldo, P. (2015). Collagen VI at a Glance. J. Cel Sci 128, 3525-3531. doi:10.1242/jcs.169748

Chi, Q., Xu, H., Song, D., Wang, Z., Wang, Z., and Ma, G. (2020). a-E-Catenin (CTNNA1) Inhibits Cell Proliferation, Invasion and EMT of Bladder Cancer. Cmar Vol. 12, 12747-12758. doi:10.2147/cmar.s259269

Choi, Y. P., Kim, B. G., Gao, M.-Q., Kang, S., and Cho, N. H. (2012). Targeting ILK and $\beta 4$ Integrin Abrogates the Invasive Potential of Ovarian Cancer. Biochem. Biophysical Res. Commun. 427, 642-648. doi:10.1016/j.bbrc.2012.09.114

Clark, D. F., Michalski, S. T., Tondon, R., Nehoray, B., Ebrahimzadeh, J., Hughes, S. K., et al. (2020). Loss-of-function Variants in CTNNA1 Detected on Multigene Panel Testing in Individuals with Gastric or Breast Cancer. Genet. Med. 22, 840-846. doi:10.1038/s41436-020-0753-1

Cox, J., Hein, M. Y., Luber, C. A., Paron, I., Nagaraj, N., and Mann, M. (2014). Accurate Proteome-wide Label-free Quantification by Delayed Normalization and Maximal Peptide Ratio Extraction, Termed MaxLFQ. Mol. Cell Proteomics 13, 2513-2526. doi:10.1074/mcp.m113.031591

Desgrosellier, J. S., and Cheresh, D. A. (2010). Integrins in Cancer: Biological Implications and Therapeutic Opportunities. Nat. Rev. Cancer 10, 9-22. doi:10.1038/nrc2748

Edoo, M. I. A., Li, J., Chen, B., Wu, J., Zhou, L., Xie, H., et al. (2019). COL6A1 Promotes Metastasis and Predicts Poor Prognosis in Patients with Pancreatic Cancer. Int. J. Oncol. 55, 391-404. doi:10.3892/ijo.2019.4825

Eke, I., and Cordes, N. (2015). Focal Adhesion Signaling and Therapy Resistance in Cancer. Semin. Cancer Biol. 31, 65-75. doi:10.1016/j.semcancer.2014.07.009

Engbrecht, M., and Mangerich, A. (2020). The Nucleolus and PARP1 in Cancer Biology. Cancers 12, 1813. doi:10.3390/cancers 12071813

Ernst, J., and Bar-Joseph, Z. (2006). STEM: a Tool for the Analysis of Short Time Series Gene Expression Data. BMC Bioinformatics 7, 191. doi:10.1186/14712105-7-191

García-Colmenero, L., González, J., Sandoval, J., Guillén, Y., Diaz-Lagares, A., Andrades, E., et al. (2020). Epigenetic Silencing of Tumor Suppressor miR-124 Directly Supports STAT3 Activation in Cutaneous T-Cell Lymphoma. Cells 9, 692. doi:10.3390/cells9122692

Gaydosik, A. M., Queen, D. S., Trager, M. H., Akilov, O. E., Geskin, L. J., and Fuschiotti, P. (2020). Genome-wide Transcriptome Analysis of the STAT6Regulated Genes in Advanced-Stage Cutaneous T-Cell Lymphoma. Blood 136, 1748-1759. doi:10.1182/blood.2019004725

Ghazawi, F. M., Netchiporouk, E., Rahme, E., Tsang, M., Moreau, L., Glassman, S., et al. (2017). Comprehensive Analysis of Cutaneous T-Cell Lymphoma (CTCL) Incidence and Mortality in Canada Reveals Changing Trends and Geographic Clustering for This Malignancy. Cancer 123, 3550-3567. doi:10.1002/ cncr.30758

Golubovskaya, V. M., and Cance, W. (2010). Focal Adhesion Kinase and P53 Signal Transduction Pathways in Cancer. Front. Biosci. 15, 901-912. doi: $10.2741 / 3653$
Hou, T., Tong, C., Kazobinka, G., Zhang, W., Huang, X., Huang, Y., et al. (2016). Expression of COL6A1 Predicts Prognosis in Cervical Cancer Patients. Am. J. Transl Res. 8, 2838-2844.

Hristov, A. C., Tejasvi, T., and Wilcox, R. A. (2019). Mycosis Fungoides and Sézary Syndrome: 2019 Update on Diagnosis, Risk-stratification, and Management. Am. J. Hematol. 94, 1027-1041. doi:10.1002/ajh.25577

Hwang, S. T., Janik, J. E., Jaffe, E. S., and Wilson, W. H. (2008). Mycosis Fungoides and Sézary Syndrome. The Lancet 371, 945-957. doi:10.1016/s0140-6736(08) 60420-1

Hyrien, O. (2016). How MCM Loading and Spreading Specify Eukaryotic DNA Replication Initiation Sites. F1000Res 5, 5. doi:10.12688/f1000research.9008.1

Jankowska-Konsur, A., Kobierzycki, C., Reich, A., Grzegrzolka, J., Maj, J., and Dziegiel, P. (2015). Expression of MCM-3 and MCM-7 in Primary Cutaneous T-Cell Lymphomas. Anticancer Res. 35, 6017-6026.

Jawed, S. I., Myskowski, P. L., Horwitz, S., Moskowitz, A., and Querfeld, C. (2014). Primary Cutaneous T-Cell Lymphoma (Mycosis Fungoides and Sézary Syndrome): Part II. Prognosis, Management, and Future Directions. J. Am. Acad. Dermatol. 70, 223-232. e1-17; quiz 240-2. doi:10.1016/j.jaad.2013.08.033

Kamijo, H., Miyagaki, T., Shishido-Takahashi, N., Nakajima, R., Oka, T., Suga, H., et al. (2018). Aberrant CD137 Ligand Expression Induced by GATA6 Overexpression Promotes Tumor Progression in Cutaneous T-Cell Lymphoma. Blood 132, 1922-1935. doi:10.1182/blood-2018-04-845834

Kanehisa, M., Sato, Y., and Morishima, K. (2016). BlastKOALA and GhostKOALA: KEGG Tools for Functional Characterization of Genome and Metagenome Sequences. J. Mol. Biol. 428, 726-731. doi:10.1016/j.jmb.2015.11.006

Kato, M., Wei, M., Yamano, S., Kakehashi, A., Tamada, S., Nakatani, T., et al. (2012). DDX39 Acts as a Suppressor of Invasion for Bladder Cancer. Cancer Sci. 103, 1363-1369. doi:10.1111/j.1349-7006.2012.02298.x

Keto, J., Hahtola, S., Linna, M., and Väkevä, L. (2021). Mycosis Fungoides and Sézary Syndrome: a Population-wide Study on Prevalence and Health Care Use in Finland in 1998-2016. BMC Health Serv. Res. 21, 166. doi:10.1186/s12913021-06109-9

Lamandé, S. R., and Bateman, J. F. (2018). Collagen VI Disorders: Insights on Form and Function in the Extracellular Matrix and beyond. Matrix Biol. 71-72, 348-367. doi:10.1016/j.matbio.2017.12.008

Lan, R., and Wang, Q. (2020). Deciphering Structure, Function and Mechanism of Lysine Acetyltransferase $\mathrm{HBO} 1$ in Protein Acetylation, Transcription Regulation, DNA Replication and its Oncogenic Properties in Cancer. Cell. Mol. Life Sci. 77, 637-649. doi:10.1007/s00018-019-03296-x

Lemchak, D., Banerjee, S., Digambar, S. S., Hood, B. L., Conrads, T. P., Jedrych, J., et al. (2018). Therapeutic and Prognostic Significance of PARP-1 in Advanced Mycosis Fungoides and Sezary Syndrome. Exp. Dermatol. 27, 188-190. doi:10.1111/exd.13477

Liu, L., Lang, Z., Wang, P., Wang, H., Cao, Y., Meng, X., et al. (2019). The Nucleosome Binding Protein 1 Promotes the Growth of Gastric Cancer Cells. J. Cancer 10, 1132-1137. doi:10.7150/jca.29292

Mendonsa, A. M., Na, T.-Y., and Gumbiner, B. M. (2018). E-cadherin in Contact Inhibition and Cancer. Oncogene 37, 4769-4780. doi:10.1038/s41388-0180304-2

Ni, X., Richmond, H. M., Liao, X. M., Decker, W. K., Shiue, L. H., Shpall, E. J., et al. (2008). Induction of T-Cell Responses against Cutaneous T-Cell Lymphomas Ex Vivo by Autologous Dendritic Cells Transfected with Amplified Tumor mRNA. J. Invest. Dermatol. 128, 2631-2639. doi:10.1038/jid.2008.125

Niranjan, K. C., Sarathy, N. A., and Alrani, D. (2018). MCM-2 Expression Differentiates Potentially Malignant Verrucous Lesions from Oral Carcinomas. Ann. Diagn. Pathol. 34, 72-76. doi:10.1016/j.anndiagpath.2018.03.001

Olsen, E., Vonderheid, E., Pimpinelli, N., Willemze, R., Kim, Y., Knobler, R., et al. (2007). Revisions to the Staging and Classification of Mycosis Fungoides and Sézary Syndrome: a Proposal of the International Society for Cutaneous Lymphomas (ISCL) and the Cutaneous Lymphoma Task Force of the European Organization of Research and Treatment of Cancer (EORTC). Blood 110, 1713-1722. doi:10.1182/blood-2007-03-055749

Pérez, C., Mondéjar, R., García-Díaz, N., Cereceda, L., León, A., Montes, S., et al. (2020). Advanced-stage Mycosis Fungoides: Role of the Signal Transducer and Activator of Transcription 3, Nuclear Factor-Kb and Nuclear Factor of Activated T Cells Pathways. Br. J. Dermatol. 182, 147-155. doi:10.1111/ bjd. 18098 
Peterson, A. C., Russell, J. D., Bailey, D. J., Westphall, M. S., and Coon, J. J. (2012). Parallel Reaction Monitoring for High Resolution and High Mass Accuracy Quantitative, Targeted Proteomics. Mol. Cell Proteomics 11, 1475-1488. doi:10.1074/mcp.o112.020131

Postnikov, Y., and Bustin, M. (2010). Regulation of Chromatin Structure and Function by HMGN Proteins. Biochim. Biophys. Acta (Bba) - Gene Regul. Mech. 1799, 62-68. doi:10.1016/j.bbagrm.2009.11.016

Quevillon, E., Silventoinen, V., Pillai, S., Harte, N., Mulder, N., Apweiler, R., et al. (2005). InterProScan: Protein Domains Identifier. Nucleic Acids Res. 33, W116-W120. doi:10.1093/nar/gki442

Rendon-Serna, N., Correa-Londono, L. A., Velasquez-Lopera, M. M., and BermudezMunoz, M. (2021). Cell Signaling in Cutaneous T-Cell Lymphoma Microenvironment: Promising Targets for Molecular-specific Treatment. Int. J. Dermat. 60, 1462-1480. Epub April 9, 2021. doi:10.1111/ijd.15451

Rochman, M., Malicet, C., and Bustin, M. (2010). HMGN5/NSBP1: a New Member of the HMGN Protein Family that Affects Chromatin Structure and Function. Biochim. Biophys. Acta (Bba) - Gene Regul. Mech. 1799, 86-92. doi:10.1016/ j.bbagrm.2009.09.012

Seto, A. G., Beatty, X., Lynch, J. M., Hermreck, M., Tetzlaff, M., Duvic, M., et al. (2018). Cobomarsen, an Oligonucleotide Inhibitor of miR-155, Co-ordinately Regulates Multiple Survival Pathways to Reduce Cellular Proliferation and Survival in Cutaneous T-Cell Lymphoma. Br. J. Haematol. 183, 428-444. doi:10.1111/bjh.15547

Sugiura, T., Nagano, Y., and Noguchi, Y. (2007). DDX39, Upregulated in Lung Squamous Cell Cancer, Displays RNA Helicase Activities and Promotes Cancer Cell Growth. Cancer Biol. Ther. 6, 957-964. doi:10.4161/cbt.6.6.4192

Trautinger, F., Eder, J., Assaf, C., Bagot, M., Cozzio, A., Dummer, R., et al. (2017). European Organisation for Research and Treatment of Cancer Consensus Recommendations for the Treatment of Mycosis fungoides/Sézary Syndrome Update 2017. Eur. J. Cancer 77, 57-74. doi:10.1016/j.ejca.2017.02.027

Wahafu, W., He, Z.-S., Zhang, X.-Y., Zhang, C.-J., Yao, K., Hao, H., et al. (2011). The Nucleosome Binding Protein NSBP1 Is Highly Expressed in Human Bladder Cancer and Promotes the Proliferation and Invasion of Bladder Cancer Cells. Tumor Biol. 32, 931-939. doi:10.1007/s13277-011-0195-0

Watany, M. M., Elmashad, N. M., Badawi, R., and Hawash, N. (2018). Serum FBLN1 and STK31 as Biomarkers of Colorectal Cancer and Their Ability to
Noninvasively Differentiate Colorectal Cancer from Benign Polyps. Clinica Chim. Acta 483, 151-155. doi:10.1016/j.cca.2018.04.038

Xing, C., Tian, H., Zhang, Y., Guo, K., Tang, Y., Wang, Q., et al. (2020). DDX39 Overexpression Predicts a Poor Prognosis and Promotes Aggressiveness of Melanoma by Cooperating with SNAIL. Front. Oncol. 10, 1261. doi:10.3389/ fonc. 2020.01261

Yan, S. P., Chu, D. X., Qiu, H. F., Xie, Y., Wang, C. F., Zhang, J. Y., et al. (2019). Retracted: LncRNA LINC01305 Silencing Inhibits Cell Epithelialmesenchymal Transition in Cervical Cancer by Inhibiting TNXBmediated PI3K/Akt Signalling Pathway. J. Cel Mol Med 23, 2656-2666. doi:10.1111/jcmm.14161

Zhang, J., Liu, J., Wu, J., Li, W., Chen, Z., and Yang, L. (2019). Progression of the Role of CRYAB in Signaling Pathways and Cancers. Ott Vol. 12, 4129-4139. doi:10.2147/ott.s201799

Zhang, Y., Liu, Z., Yang, X., Lu, W., Chen, Y., Lin, Y., et al. (2021). H3K27 Acetylation Activated-Col6al Promotes Osteosarcoma Lung Metastasis by Repressing STAT1 and Activating Pulmonary Cancer-Associated Fibroblasts. Theranostics 11, 1473-1492. doi:10.7150/thno.51245

Conflict of Interest: The authors declare that the research was conducted in the absence of any commercial or financial relationships that could be construed as a potential conflict of interest.

Publisher's Note: All claims expressed in this article are solely those of the authors and do not necessarily represent those of their affiliated organizations, or those of the publisher, the editors and the reviewers. Any product that may be evaluated in this article, or claim that may be made by its manufacturer, is not guaranteed or endorsed by the publisher.

Copyright (c) 2021 Gan, Shi, Zhang, Sun and Chen. This is an open-access article distributed under the terms of the Creative Commons Attribution License (CC BY). The use, distribution or reproduction in other forums is permitted, provided the original author(s) and the copyright owner(s) are credited and that the original publication in this journal is cited, in accordance with accepted academic practice. No use, distribution or reproduction is permitted which does not comply with these terms. 